\title{
Evaluation of the CPR video decision aid with patients with end stage renal disease
}

\author{
Cherie Kapell Brown ${ }^{1}$, Jennifer Kryworuchko ${ }^{2^{*}}$ (I) and Wanda Martin ${ }^{3}$
}

\begin{abstract}
Background: People with end stage renal disease (ESRD) face important health-related decisions concerning endof-life care and the use of life-support technologies. While people often want to be involved in making decisions about their health, there are many challenges. People with advanced illness may have limited or wavering ability to participate fully in decision-making conversations - or lack decisional capacity for making decisions. Additionally, they may have a limited understanding of CPR and tend to receive inconsistent information on the process and outcome of CPR. Unfortunately, these discussions are often avoided. Shared decision-making approaches are an approach to overcoming these challenges. The objectives of this research was to design, test, and analyze a novel CPR video decision aid (VDA) with nephrology patients and their families in a clinical setting.

Methods: The Interprofessional Shared Decision-making Model was used as a framework to guide the research. A prospective quasi-experimental design included pre/posttest measures of knowledge and confidence in decisionmaking, and posttest only measure of uncertainty about the decision.

Results: Participant knowledge about CPR increased from a mean score of 4.8/9 (standard deviation [SD] = 1.65) before viewing the video to $7.5 / 9(S D=1.40)(p=0.000)$ after viewing the video. Decisional self-efficacy improved slightly from $84 \%$ pre intervention (SD 17.04, range 20-100) to 86\% after the intervention (SD 14.13, range 39-100) $(p=0.005)$ for patient participants. Before the intervention, most patients $(43 / 49 ; 86 \%)$ had an order to have CPR in the physician orders and very few $(7 / 49 ; 14 \%)$ had an order not to have CPR. Immediately after viewing the CPRVDA and completing the values clarification worksheet, fewer 28/49 (57\%) chose to have CPR, 13 (27\%) chose not to have CPR and 8 (16\%) were unsure.

Conclusions: The CPR-VDA was feasible and acceptable to patients with ESRD, their families and the healthcare team. The CPR-VDA positively affected decision-making: improving patient and family knowledge about CPR, clarity of values, patients' decisional self-efficacy, the congruence between documented physician's orders and patient choice, quality of communication about CPR, while reducing decisional conflict (uncertainty) amongst patients, families, and physicians.
\end{abstract}

Keywords: Decision-aid, Quality of communication, CPR, End-of-life, Shared decision-making

\section{Background}

Patients with end stage renal disease (ESRD) face important health related decisions, such as decisions about treatment options, palliative end-of-life care and whether life-support technologies are wanted in their care [1]. ESRD is the final stage of kidney disease where kidneys are working at less than $15 \%$ of their normal capacity,

\footnotetext{
* Correspondence: jennifer.kryworuchko@ubc.ca

${ }^{2}$ School of Nursing and Centre for Health Services and Policy Research, The University of British Columbia, T275- 2211 Wesbrook Mall, Vancouver, BC V6T 2B5, Canada

Full list of author information is available at the end of the article
}

therefore requiring intervention to sustain life [2]. All patients with ESRD have had to make decisions through the course of their chronic illness, for example, about screening and diagnostic tests, vascular access, or dialysis modalities. The use of an additional life supportive technology such as cardiopulmonary resuscitation (CPR), if cardiac or respiratory arrest occurs is another important decision for people with ESRD during their healthcare journey. The aim of this study was to improve the quality of communication during CPR decision-making processes

(c) The Author(s). 2018 Open Access This article is distributed under the terms of the Creative Commons Attribution 4.0 International License (http://creativecommons.org/licenses/by/4.0/), which permits unrestricted use, distribution, and 
involving patients with ESRD, their families and the healthcare team.

Patients with ESRD have a higher incidence of cardiac arrest because dialysis treatment exacerbates cardiac disease. Healthcare providers may offer CPR to try to restore cardiac and respiratory function and prolong life [3]. Unfortunately, CPR does not work very well for patients with advanced medical illness like ESRD and has poor prognosis $[4,5]$. Higher initial survival can be observed after cardiac arrest in a hemodialysis unit compared to other hospital settings and this may be attributed to availability of equipment, personnel, and vascular access [5]. However, overall survival after cardiac arrest for older adults, regardless of setting, with advanced chronic illness such as kidney disease remains poor, with less than $20 \%$ of patients who receive CPR surviving to hospital discharge [6-8].

Jones, Podolsky, and Green [9] argue that the health care system has not responded with sufficient education, engagement, and support in the decision-making process. As patients and family members increasingly are called upon to make complex decisions, they are challenged by a lack of medical knowledge, low health literacy, and uncertainty about their prognosis. Indeed, for medical, social, cultural, and legal reasons, many physicians are reluctant to meaningfully engage patients nearing end-of-life in advance care planning [9]. What has followed is a potentially unwanted increase in technological care at the end-of-life.

For example, when asked, patients maintain they would prefer less aggressive care if death were likely in the short term [10]. ESRD patients and their families feel they are not always part of discussions around prognosis, treatment goals, and end-of-life care [11, 12]. Almost 30\% of patients over 75 years of age prefer to stop dialysis because they experience unacceptably poor quality of life and therapy intolerance [13]. There is also increasing awareness that resources and spending at end-of-life are not well correlated with quality of life or quality of care [14]. Canadians, older patients, and health care professionals increasingly are focused on meaningful advance care planning and promoting a shared, informed decisionmaking process about the use of technology at the end-of-life.

The CPR video decision aid (VDA) is a novel approach to shared decision-making preparing patients, families, and their healthcare professionals for conversations about the CPR decision. Patient decision aids are resources that can identify evidence-based healthcare options, their benefits and harms, and further assist patients to communicate their values and preferences to their healthcare provider [15]. With the use of decision aids, patients have a better understanding about care options and anticipated outcomes, have improve perceived risk, experience a good match between values and choices, and show a reduction in indecision and regret that leads to decisional conflict [16].

This study consisted of field-testing the CPR-VDA in a community context with ESRD patients who have already made a similar complex decision to receive dialysis. The study was part of a larger research program aimed at improving the quality of communication during decision-making processes involving patients with advanced illness, their families, and the healthcare team. The aim of this study was twofold: to improve patient and family member knowledge and involvement in decisions about CPR, and to ensure that CPR was provided only when wanted. The hypothesis was that the CPR-VDA would be acceptable to patients and feasible to use to prepare ESRD patients for shared decisionmaking about CPR. The video would also improve patient and family knowledge, clarify values, and thus improve congruence between documented orders and patient choice. The patient and their family member would experience minimal residual uncertainty about the decision thereby improving confidence to make the decision.

\section{Methods \\ Design}

A prospective quasi-experimental design included pre/ posttest measures of knowledge and confidence in decision-making, and posttest only measure of uncertainty about the decision (decisional conflict). Research Ethics Board approval was obtained prior to commencing the study (BEH 13-200) and all participants provided written informed consent. The study was also approved by the local patient and family advisory council and health authority partners.

\section{Setting and participants}

Participants were recruited between late summer and mid-winter 2015 in an urban inpatient and outpatient hemodialysis center. At these centers, 260 patients receive hemodialysis 6 days per week. A convenience sample of eight physicians who cared for patients with ESRD receiving dialysis was recruited from the hemodialysis centers. Eligible physicians were staff physicians (nephrologists) or residents on their nephrology rotation. Recruited physicians and members from the renal health care team (social worker, clinical nurse specialist, and unit manager) helped identify eligible patients in the hemodialysis program and/or family members and introduced the study. The research nurse then determined the final eligibility of patients and family members who expressed desire to participate.

Eligible patients were over 55 years of age, had stage 5 renal failure, were dependent on dialysis, and could communicate in English. Patients were invited to identify the 
adult 'family' member who knew them best, including partners, significant others, and/or close friends. The family member had to be 18 years or older, speak and understand English, have capacity to make healthcare decisions, have accompanied the patient to dialysis at least once, and have provided assistance to the patient without pay. Ideally, we wanted to recruit dyads consisting of a patient and their family member with whom they shared healthcare decisions. However, willing patients who could consent were included even without the participation of a family member. Patients without decisional capacity were invited to assent to participate if their family member was a participant.

\section{Intervention}

The CPR-VDA is a seven-minute video designed for participants to independently view on a portable screen. The video presents information about CPR and the alternative option (comfort care) as well as information about the patient experience and important health outcomes. A CPR decision worksheet, which included a values clarification exercise, tailored the generic patient decision aid format to the CPR decision, and was completed with the study nurse. A plain language script for the CPR-VDA was a significant adaptation from an earlier paper-based CPR information tool [17], and was informed by a rapid systematic review process of CPR outcomes data. In collaboration with the research team, a cinematographer produced the final video CPR-VDA that is publicly available at http://vimeo.com/48147363. The study nurse provided non-directive support to help participants complete the questionnaires thus preparing them for the discussion with the physician, consistent with the role of a decision coach in a shared decision framework [18].

\section{Procedure}

The study nurse conducted interviews during a scheduled dialysis treatment. The interview commenced with the patient and/or family member once dialysis was initiated and the patient remained physically stable (Table 1). After obtaining consent, a brief chart review was conducted to check documented CPR orders and pertinent health history. Interviews occurred in a semi private place with patients, family, and staff in close proximity.

The first part of the questionnaires included; demographics with a self-reported frailty index and health literacy test, pre-knowledge test about CPR and preintervention self-efficacy questions. Following this series of questions, the patient and/or family member viewed the seven-minute CPR-VDA video on an iPad screen. The interview continued with acceptability questions regarding the CPR-VDA video, post-knowledge test questions about CPR, post-decision self-efficacy questions and series of questions to assess any decision conflict related to the CPR decision. The study nurse asked patients their CPR preference after viewing the CPR-VDA and completing the values clarification worksheet.

\section{Outcomes}

Acceptability was assessed using eight validated questions about use, amount of information, the length, the clarity, balance in presentation, willingness to recommend to

Table 1 Data Collection Strategy

\begin{tabular}{lll}
\hline Data source & Time period for data collection & Collection tool \\
\hline $\begin{array}{l}\text { Participating Patient / } \\
\text { Family }\end{array}$ & Pre VDA intervention & PART A: Demographics, Frailty Index, Health Literacy Score \\
& & Knowledge about CPR \\
& Decisional Self-efficacy \\
& CPR-VDA Intervention & View CPR-VDA (http://vimeo.com/48147363) \\
& Observation Matrix (i.e., elements of capacity, fatigue, \\
& attention) \\
& Post VDA intervention & PART B: Acceptability Survey \\
& Knowledge about CPR \\
& Decisional Conflict Scale \\
& Decisional Self-efficacy Scale \\
& CPR Worksheet
\end{tabular}

Participating Physician Post VDA intervention and discussion

Medical record of participating patient

Study Nurse
At enrollment (consent) and 1 week from date of enrollment

Initiated at time of enrollment until end of participation
PART A: Demographics (completed once only per physician) PART B: Physician Survey (completed after engaging in each discussion about CPR: Decisional Conflict Scale)

Chart Abstraction Tool (co-morbid illnesses, the presence of 'Goals of Care' orders, 'DNR' orders, 'Resuscitation Care-plan' orders and any order related to (PR)

Field notes 
others and overall suitability for decision-making [19, 20]. Knowledge about CPR was tested using nine questions developed by the research team. Self-Efficacy is the participants' self-confidence or belief in their abilities in decision-making, and was measured using the Decision Self-Efficacy Scale [21]. The scale gave a total score out of 100 , and a higher score indicates higher self-efficacy for decision-making. Used to evaluate a decision aid for women with osteoporosis, the reliability of the scale was 0.92 and it correlated with decisional conflict subscales of feeling informed $(r=0.47)$ and supported $(r=0.45)$ [21]. Decision conflict was also assessed, which occurs when a patient is uncertain about what course of action is best for them [22]. The perception of uncertainty is related to modifiable factors such as feeling uninformed, being unclear about personal values for the options, or feeling unsupported in decision-making [22]. Decision conflict was measured using the low literacy version of the Decision Conflict Scale for patient/family [22] where scores lower than 25/ 100 were associated with decision implementation and scores over 37.5/100 were associated with delayed decisions. The scale has a reliability of 0.78 and has been used in many studies of patient decision aids [16, 22]. Decisional conflict was also measured using the SURE test [23] in the values clarification worksheet. The reliability of this scale is 0.65 [23]. Measurement of relevancy of the CPR decision for the patient at this stage of their healthcare journey was asked before and after viewing the video. After participant(s) completed the pre and posttest questionnaires, they were then invited to complete the paper based values clarification worksheet.

Once all patient/family questionnaires were completed, the physician caring for the patient discussed CPR with the patient and/or family member to assess whether or not they wanted CPR in the event of a cardiac or respiratory arrest. The research nurse observed this discussion and completed an Observing Patient Involvement (OPTION) tool that assessed physician and patient involvement in shared decision-making. The OPTION instrument was developed to evaluate shared decision-making communication and the reliability of this scale was 0.66 in a study evaluating physician encounters in primary care settings [24]. Responses on a five-point scale ranged from 'the behavior is not observed' to 'observed and executed to a high standard'. The total summed score range from zero to 48 with higher scores indicating greater competency in shared decision-making [24]. Physicians completed a final questionnaire to report on the communication with patient/family. During the interview time, the study nurse used an observation matrix and field notes. The matrix captured observations such as time of day, distractions, and local environment, before and after the CPR-VDA intervention. The data collection strategy is summarized in Table 1.

\section{Statistical analysis}

Baseline characteristics and outcomes were reported using proportions for categorical variables, and means and standard deviations (SD) for continuous variables. For each outcome of interest, analysis was conducted at the participant level using descriptive statistics and when appropriate, a paired sample t-test for comparing means (before/after). Data management and statistical analyses were conduct using IBM SPSS Statistics (Version 23).

\section{Results \\ Demographics}

Of those invited to participate, $8 / 8(100 \%)$ physicians accepted, 49/53 (92\%) patients accepted, and 8/9 (89\%) family members accepted (Table 2). Of the five people who declined to participate, four were not interested and one patient was unable to complete the interview due to declining health status. There were seven patient/family member dyads and one family member who participated without the patient. Physicians were mostly experienced clinical nephrology staff and some had either palliative care experience or training about goals of care communication. Fewer than half of patients were female, half were married, and the average age was 67 years. Most patients lived in their own home in an urban setting where they received dialysis. Still, one third of the patients were from a rural area and travelled into the city for treatment. Patients had relatively high health literacy score despite having high school or less education. Over half of patients considered themselves vulnerable to severely frail and most had prior communication about CPR, which varied in formality.

\section{Feasibility and acceptability}

All patient and family member participants viewed the CPR-VDA and completed the values clarification worksheet during the interview time. Each had a follow-up discussion with their physician, although the discussion did not always occur on the same day as the initial interview. After viewing the CPR-VDA and completing the worksheet, participants were clear about the necessary decision, knew the options, could articulate their values, and could discuss these in varying degrees of detail. They were also able to identify their support person(s), decision-making needs and make a plan for next steps. During the video viewing, challenges included poor lighting, disruptive noise, physical discomfort (i.e., vascular access in their arm / needle in arm) positioning for treatment, fatigue, thirst, and confusion over wording. Multiple interruptions in the busy environment affected some people's ability to attend to detail during the interview / intervention process resulting in $6 \%(3 / 49)$ of patients needing to review parts of the video. While working through the values clarification worksheet, participants revealed emotional struggles surrounding their current health state and concerns about the future. 
Table 2 Demographics - Patient and Family

\begin{tabular}{|c|c|c|}
\hline Demographic & Patient $n=49$ & Family $n=8$ \\
\hline Age M (range, SD) & $67(55-91,9.66)$ & $62(48-72,8.19)$ \\
\hline Female n (\%) & $21(43 \%)$ & $5(63 \%)$ \\
\hline \multicolumn{3}{|l|}{ Marital Status } \\
\hline Married or living as married & $28(57 \%)$ & $8(100 \%)$ \\
\hline Widowed & $10(21 \%)$ & 0 \\
\hline Never married & $5(10 \%)$ & 0 \\
\hline Divorced or separated & $6(12 \%)$ & 0 \\
\hline Rural & $15(31 \%)$ & $5(63 \%)$ \\
\hline Urban & $34(69 \%)$ & $3(37 \%)$ \\
\hline \multicolumn{3}{|l|}{ Living Arrangement } \\
\hline Home & $36(74 \%)$ & $8(100 \%)$ \\
\hline Retirement residence & $8(16 \%)$ & 0 \\
\hline Long-term care or nursing home & $4(8 \%)$ & 0 \\
\hline Assisted living & $1(2 \%)$ & 0 \\
\hline \multicolumn{3}{|l|}{ Highest Education } \\
\hline Elementary school or less & $3(6 \%)$ & 0 \\
\hline Some high school & $17(35 \%)$ & $1(12.5 \%)$ \\
\hline High school graduate & $11(24 \%)$ & $4(50 \%)$ \\
\hline Some college/trade school & $8(16 \%)$ & 0 \\
\hline College/trade school diploma & $2(4 \%)$ & 0 \\
\hline Some university & $4(8 \%)$ & $1(12.5 \%)$ \\
\hline University graduate & $4(8 \%)$ & $1(12.5 \%)$ \\
\hline Graduate degree & 0 & $1(12.5 \%)$ \\
\hline Health Literacy (out of 8) M (range, SD) & $6.61(0-8,2.42)$ & $8(8,0)$ \\
\hline \multicolumn{3}{|l|}{ Importance of Religion n (\%) } \\
\hline Extremely important & $6(12 \%)$ & $1(12.5 \%)$ \\
\hline Very important & $16(33 \%)$ & $3(37.5 \%)$ \\
\hline Somewhat important & $14(29 \%)$ & $3(37.5 \%)$ \\
\hline Not very important & $8(16 \%)$ & $1(12.5 \%)$ \\
\hline Not at all important & $4(8 \%)$ & 0 \\
\hline Don't know & $1(2 \%)$ & 0 \\
\hline Prior communication about CPR? Yes & $30(61 \%)$ & $6(75 \%)$ \\
\hline \multicolumn{3}{|l|}{ Patient Frailty } \\
\hline Very fit & 0 & \\
\hline Well & $3(6 \%)$ & \\
\hline Managing well & $19(39 \%)$ & \\
\hline Vulnerable & $18(36 \%)$ & \\
\hline Mildly frail & $5(11 \%)$ & \\
\hline Moderately frail & $2(4 \%)$ & \\
\hline Severely frail & $2(4 \%)$ & \\
\hline
\end{tabular}

$M$ mean, $S D$ standard deviation

Participants were asked how relevant the decision about CPR was for them before and after the intervention, and while the average rating was that it was relevant to them
$(2 / 5)$, the mean score increased from 2.1 to $2.3(p=0.01)$ after the intervention. Ninety-eight percent $(56 / 57)$ of patient and family member participants rated the CPR-VDA 
as good to excellent. Seventy-seven percent (44/57) stated it contained the right amount of information, 75\% (43/57) thought the information in the video was completely balanced, and 93\% (53/57) found the information presented about CPR to be clear. The CPR-VDA was helpful in making decisions about CPR for 89\% (51/57) of participants and almost everyone (98\%) would recommend the video to other people who are considering CPR (Table 3).

\section{Effectiveness of the decision aid}

Participant knowledge about CPR increased from a mean score of $4.8 / 9$ (standard deviation $[\mathrm{SD}]=1.65$ ) before viewing the video to $7.5 / 9(\mathrm{SD}=1.40)(p=0.000)$ after viewing the video. Decisional self-efficacy improved slightly from $84 \%$ pre intervention (SD 17.04, range 20 100 ) to $86 \%$ after the intervention (SD 14.13, range 39100) $(p=0.005)$ for patient participants; however, family members' scores remained high in both periods (Table 4). Decisional conflict scores were relatively low overall (scores could range from 0 [no decisional conflict] to 100 [extremely high decisional conflict]); they were higher amongst patients (mean score of $13.57, \mathrm{SD}=$ 18.34, range 0-70) but very low amongst family members (mean score of $1.25, \mathrm{SD}=3.54$, range $0-10$ ). Decisional conflict was also measured for patients using the clinical SURE test on the values clarification worksheet: 14. (28\%) patients reported experiencing decisional conflict while 36 (72\%) reported no decisional conflict.

Before the intervention, most patients (43/49; 86\%) had an order to have CPR in the physician orders and very few $(7 / 49 ; 14 \%)$ had an order not to have CPR. Immediately after viewing the CPR-VDA and completing the values clarification worksheet, fewer 28/49 (57\%) chose to have CPR, 13 (27\%) chose not to have CPR and $8(16 \%)$ were unsure. Final chart review 1 week later revealed that fewer patients wanted CPR 36/50 (72\%) and more patients $14(28 \%)$ had an order not to have CPR $(p=0.007)$. As is typical in clinical practice, those participants who are unsure will have the default order to have CPR placed in their chart.

After the intervention, a physician discussed the CPR decision with the patient and/or family member with variable quality of patient involvement as assessed using OPTION ( $\mathrm{M}=25.66 \mathrm{SD} 7.41$, range 9-47, maximum score possible 48). These discussions were held during the patient's dialysis treatment with others (i.e., family, nurse, pharmacist, social work, clinical coordinator, as well as other patients and their families) present in 31/ $49(62 \%)$ patient conversations. Only the physician and participants were directly involved in the CPR conversation. This is usual practice as the dialysis unit is mostly an open observation unit. In the exit survey, physicians reported the CPR decision as "very relevant" to their patients $(\mathrm{M}=3.60, \mathrm{SD}=0.53$, range $=2-4)$, were "very satisfied" with the discussion they had after the intervention $(\mathrm{M}=3.18, \mathrm{SD}=0.79$, range $=1-4)$, and reported that the overall discussion was "easy" to have with their patient $(\mathrm{M}=0.80, \mathrm{SD}=0.80$, range $=0-3)($ Table 4$)$.

\section{Discussion}

This was the first study to evaluate the use of the CPR-VDA specifically with patients diagnosed with ESRD. Patients with ESRD and their family members valued the CPR-VDA as a tool to help inform and consider decisions about CPR. The initial plan was to recruit patient and family dyads to participate in the study. However, it was extremely challenging to engage both partners during routine dialysis treatments. Those family members who did participate had special appointments for them to be at a specific treatment. Patients and family members found the CPR-VDA acceptable to use, even when patients' illness and treatment caused difficulty attending to all aspects of the decision-making process all of the time. For the most part, people rated the intervention excellent, contained the right amount of information, balanced, clear, helpful, and would recommend it to others.

The CPR-VDA significantly improved knowledge about the CPR decisions. When combined with the values clarification worksheet, the CPR-VDA helped patients consider the options from their own perspective, integrate their own values, highlighted other supports and considerations, supported their confidence in decision-making, and reduced decisional conflict. Our observations are consistent with results of a recent systematic review about the effectiveness of patient decision aids [16]. Patient decision aids as a class of intervention are known to improve understanding about healthcare and treatment choices and resulting outcomes, understand risks better, integrate values with their choices, and reduce uncertainty and remorse about the decision [16].

Patients were effectively able to utilize the CPR-VDA despite lower formal educational levels. They were continuously able to attend to details in a hectic treatment environment while experiencing considerable health challenges, and varying levels of frailty. Video format patient decision aids may support patients with lower health literacy due to their oral format and flexibility since participants could start, stop, and rewind the video. Furthermore, participants were supported by both an explicit values clarification exercise and a study nurse acting as a decision coach. These findings support evidence from other studies suggesting video decision aids help patients and families make informed medical treatment decisions [25-27].

As decision coach, the study nurse provided important support to patients and families. Patient participants had difficulty navigating questionnaires due to vascular 
Table 3 Acceptability of CPR-VDA

\begin{tabular}{|c|c|c|c|}
\hline & \multicolumn{3}{|l|}{ Patient $n=49$} \\
\hline & Pre & Post & $p$-value \\
\hline Relevance of the CPR decision M (range, SD) (Not relevant 0-1-2-3-4 Very relevant) & $2.1(0-4,1.1)$ & $2.3(0-4,1.1)$ & 0.01 \\
\hline Item & \multicolumn{2}{|c|}{ Patient $n=49 \mathrm{n}(\%)$} & Family $n=8 \mathrm{n}(\%)$ \\
\hline \multicolumn{4}{|l|}{ "How would you rate the CPR video decision aid?" } \\
\hline Poor & \multicolumn{2}{|l|}{0} & 0 \\
\hline Fair & \multicolumn{2}{|l|}{$1(2 \%)$} & 0 \\
\hline Good & \multicolumn{2}{|l|}{$19(38 \%)$} & $3(37.5 \%)$ \\
\hline Very good & \multicolumn{2}{|l|}{$20(40.8 \%)$} & $4(50 \%)$ \\
\hline Excellent & \multicolumn{2}{|l|}{$9(18.4 \%)$} & $1(12.5 \%)$ \\
\hline \multicolumn{4}{|l|}{ "How would you rate the amount of information in the video?" } \\
\hline Much less than I needed & \multicolumn{2}{|l|}{0} & 0 \\
\hline A little less than I needed & \multicolumn{2}{|l|}{$4(8.2 \%)$} & 0 \\
\hline About the right amount & \multicolumn{2}{|l|}{$37(75.5 \%)$} & $7(87.5 \%)$ \\
\hline A little more than I needed & \multicolumn{2}{|l|}{$6(12.2 \%)$} & 0 \\
\hline A lot more than I needed & \multicolumn{2}{|l|}{$2(4.1 \%)$} & $1(12.5 \%)$ \\
\hline \multicolumn{4}{|l|}{ "How balanced was the video's information about CPR?" } \\
\hline Clearly slanted towards having CPR & \multicolumn{2}{|l|}{$4(8.2 \%)$} & 0 \\
\hline A little slanted towards having CPR & \multicolumn{2}{|l|}{$4(8.2 \%)$} & $1(12.5 \%)$ \\
\hline Completely balanced & \multicolumn{2}{|l|}{$38(77.6 \%)$} & $5(62.5 \%)$ \\
\hline A little slanted towards not having CPR & \multicolumn{2}{|l|}{$3(6.1 \%)$} & $2(25 \%)$ \\
\hline Clearly slanted towards not having CPR & \multicolumn{2}{|l|}{0} & 0 \\
\hline \multicolumn{4}{|l|}{ "How clear was the information in the video?" } \\
\hline Everything was clear & \multicolumn{2}{|l|}{$29(59.2 \%)$} & $7(87.5 \%)$ \\
\hline Most things were clear & \multicolumn{2}{|l|}{$17(34.7 \%)$} & 0 \\
\hline Some things were clear & \multicolumn{2}{|l|}{$2(4.1 \%)$} & $1(12.5 \%)$ \\
\hline Many things were unclear & \multicolumn{2}{|l|}{$1(2 \%)$} & 0 \\
\hline \multicolumn{4}{|l|}{ "How helpful was the video in helping you make decisions about CPR?" } \\
\hline Very helpful & \multicolumn{2}{|l|}{$28(57.1 \%)$} & $4(50 \%)$ \\
\hline Somewhat helpful & \multicolumn{2}{|l|}{$16(32.7 \%)$} & $3(37.5 \%)$ \\
\hline A little helpful & \multicolumn{2}{|l|}{$5(10.2 \%)$} & 0 \\
\hline Not helpful & 0 & & $1(12.5 \%)$ \\
\hline "Would you recommend this video to other people who are considering CPR?" & & & \\
\hline I would definitely recommend it & $40(81.6 \%)$ & & $6(75 \%)$ \\
\hline I would probably recommend it & $8(16.3 \%)$ & & $2(25 \%)$ \\
\hline I would probably not recommend it & $1(2 \%)$ & & 0 \\
\hline I would definitely not recommend & 0 & & 0 \\
\hline
\end{tabular}

access in their arm, poor lighting, positioning for treatment, and fatigue. Thus the study nurse had a dual role in supporting them to view the video and could not help but to form a therapeutic relationship that included empathetic listening. She was able to focus on subtle changes in patient health status and adjust pacing or timing accordingly, as well as being able to give further clarification when needed. Activating other members of the healthcare team besides the physician may also be of benefit, but was not captured in this efficacy study.

Physicians reinforced the work of the study nurse and the CPR-VDA intervention during their discussion with the patient after the intervention. Thus, the study nurse as decision coach had an explicit and formal role on the interprofessional team regarding decision-making. Optimizing the decision-making environment to increase a patient's ability to engage meaningfully in DM was a 
Table 4 Effectiveness of the Decision Aid

\begin{tabular}{|c|c|c|c|c|c|c|}
\hline \multirow[t]{2}{*}{ Outcome } & \multicolumn{3}{|l|}{ Patient $n=49$} & \multicolumn{3}{|l|}{ Family $n=8$} \\
\hline & Pre & Post & $p$-value & Pre & Post & $p$-value \\
\hline \multicolumn{7}{|l|}{ CPR test questions $n(\%)$ correct answers } \\
\hline $\begin{array}{l}\text { 1. When the heart stops beating, brain death will } \\
\text { occur in: several minutes. }\end{array}$ & $23(47 \%)$ & $40(81 \%)$ & & $5(63 \%)$ & $6(75 \%)$ & \\
\hline $\begin{array}{l}\text { 2. CPR includes the following treatments: } \\
\text { pressing hard and fast on the breastbone } \\
\text { to pump blood through the heart to the body. }\end{array}$ & $39(80 \%)$ & $46(94 \%)$ & & $7(88 \%)$ & $8(100 \%)$ & \\
\hline $\begin{array}{l}\text { 3. If CPR is successful and the heart restarts } \\
\text { the person: usually needs a machine to help } \\
\text { with breathing, medicines, and fluids while } \\
\text { trying to recover in ICU (Intensive Care Unit). }\end{array}$ & $18(37 \%)$ & $39(80 \%)$ & & $1(13 \%)$ & $6(75 \%)$ & \\
\hline $\begin{array}{l}\text { 4. The most serious possible harm from } \\
\text { the heart stopping and needing to have CPR is: } \\
\text { severe brain damage from lack of oxygen }\end{array}$ & $32(65 \%)$ & $42(86 \%)$ & & $4(50 \%)$ & $8(100 \%)$ & \\
\hline $\begin{array}{l}\text { 5. When CPR is effective it will: restart the heart } \\
\text { but have absolutely no effect on other medical conditions. }\end{array}$ & $25(51 \%)$ & $39(80 \%)$ & & $8(100 \%)$ & $8(100 \%)$ & \\
\hline $\begin{array}{l}\text { 6. If } 100 \text { people have a chronic condition } \\
\text { (heart failure, kidney failure, chronic lung disease) } \\
\text { and their heart stops, how many will survive } \\
\text { CPR and recover well enough to leave the hospital?: } \\
\text { very few people (10 out of } 100 \text { ). }\end{array}$ & $15(31 \%)$ & $43(88 \%)$ & & $3(38 \%)$ & $8(100 \%)$ & \\
\hline $\begin{array}{l}\text { 7. If the patient decides NOT to have CPR: they } \\
\text { can receive treatments to relieve suffering AND for } \\
\text { other medical conditions if wanted. }\end{array}$ & $25(51 \%)$ & $43(88 \%)$ & & $6(75 \%)$ & $7(88 \%)$ & \\
\hline $\begin{array}{l}\text { 8. The healthcare team wants to talk to hospitalized } \\
\text { patients about the CPR decision because: the right } \\
\text { decision about CPR depends on what is most } \\
\text { important to the individual patient in addition to } \\
\text { the patient's medical conditions. }\end{array}$ & $28(57 \%)$ & $43(88 \%)$ & & $5(63 \%)$ & $7(88 \%)$ & \\
\hline $\begin{array}{l}\text { 9. Of all the people who survive CPR, how } \\
\text { many will have severe brain damage?: a few survivors. }\end{array}$ & $30(61 \%)$ & $34(69 \%)$ & & $5(63 \%)$ & $7(88 \%)$ & \\
\hline Knowledge (out of 9) M (range, SD) & $4.8(0-8,1.65)$ & $7.5(4-9,1.40)$ & 0.000 & $5.6(4-7,1.31)$ & $8.1(6-9,0.99)$ & 0.000 \\
\hline $\begin{array}{l}\text { Decisional Self-Efficacy }(0=\text { extremely low; } \\
100=\text { extremely high) M (range, SD) }\end{array}$ & $\begin{array}{l}84(20-100, \\
17.04)\end{array}$ & $\begin{array}{l}86(39-100, \\
14.13)\end{array}$ & 0.005 & $\begin{array}{l}86(52-100 \\
15.98)\end{array}$ & $\begin{array}{l}92(77-100, \\
8.23)\end{array}$ & 0.203 \\
\hline \multicolumn{7}{|l|}{ Certainty } \\
\hline $\begin{array}{l}\text { Decisional conflict scale }(0=\text { no conflict; } \\
100=\text { high conflict) } M(\text { range, SD) }\end{array}$ & & $\begin{array}{l}13.57(0-70 \\
18.34)\end{array}$ & & & $\begin{array}{l}1.25(0-10 \\
3.54)\end{array}$ & \\
\hline \multicolumn{7}{|l|}{ SURE n (\%) } \\
\hline 4 (no decisional conflict) & & $36(72 \%)$ & & & & \\
\hline 3 & & $6(12 \%)$ & & & & \\
\hline 2 & & $3(6 \%)$ & & & & \\
\hline 1 & & $3(6 \%)$ & & & & \\
\hline 0 (high decisional conflict) & & $2(4 \%)$ & & & & \\
\hline \multicolumn{7}{|l|}{ Preference n (\%) } \\
\hline Have CPR & & $28(57 \%)$ & & & & \\
\hline No CPR & & $13(27 \%)$ & & & & \\
\hline Unsure & & $8(16 \%)$ & & & & \\
\hline \multicolumn{7}{|l|}{ Physician Order n (\%) } \\
\hline Have $C P R=1$ & $43(86 \%)$ & $36(72 \%)$ & & & & \\
\hline No $C P R=2$ & $7(14 \%)$ & $14(28 \%)$ & & & & \\
\hline M (range, SD) & $1.14(1-2,0.35)$ & $1.28(1-2,0.45)$ & 0.007 & & & \\
\hline
\end{tabular}


Table 4 Effectiveness of the Decision Aid (Continued)

\begin{tabular}{|c|c|c|c|c|c|c|}
\hline \multirow[t]{2}{*}{ Outcome } & \multicolumn{3}{|c|}{ Patient $n=49$} & \multicolumn{3}{|c|}{ Family $n=8$} \\
\hline & Pre & Post & $p$-value & Pre & Post & $p$-value \\
\hline \multicolumn{7}{|l|}{$\begin{array}{l}\text { Observation of } 50 \text { single interactions between } \\
\text { each patient/family and physician }\end{array}$} \\
\hline OPTION (score out of 48) M (range, SD) & \multicolumn{6}{|c|}{$25.66(9-47,7.41)$} \\
\hline \multicolumn{7}{|l|}{ Physician Exit Survey } \\
\hline $\begin{array}{l}\text { Relevance of the CPR decision for } \\
\text { my patient M (range, SD) } \\
\text { (Not relevant 0-1-2-3-4 Very relevant) }\end{array}$ & \multicolumn{6}{|c|}{$3.60(2-4,0.53)$} \\
\hline $\begin{array}{l}\text { Satisfaction felt with discussion about } \\
\text { CPR with patient M (range, SD) } \\
\text { (Not at all 0-1-2-3-4 Completely) }\end{array}$ & \multicolumn{6}{|c|}{$3.18(1-4,0.79)$} \\
\hline $\begin{array}{l}\text { Overall experience with the CPR discussion } \\
\text { M (range, SD) (Very easy 0-1-2-3-4 Very Difficult) }\end{array}$ & \multicolumn{6}{|c|}{$0.80(0-3,0.80)$} \\
\hline
\end{tabular}

clear role for the study nurse providing decision support in this study, and could be taken on by nurses who are part of the clinical team. In this case, the study nurse was an experienced ICU nurse with additional decision coaching training. It is likely that dialysis nurses would need additional preparation or release time to take on the additional role that is fully within their scope of practice. Nurses have a clear ethical and professional obligation to support healthcare decision-making [28] and their expertise in communications and establishing therapeutic relationships could be utilized to facilitate healthcare decision-making.

While there is much to gain from understanding the use of decision-aids with patients in the dialysis setting, there are limitations to this study. The homogenous sample limits generalization of results to other populations. Recruitment of dyads of patient and family member was challenging because they were busy and not always present at dialysis appointments. Question fatigue was evident among the participants and future studies with this patient population may wish to utilize video or audio recordings to limit fatigue in answering the questions and eliminate the need of the study nurse manually recording answers during the interview. Although there was evidence of above average shared decision-making during the interview and most physicians alluded to the CPR-VDA, the assessment of the patient-physician interview was a very limited measurement as it only considered one interaction between the patient and physician. The conversation was taken out of context of any previous relationship development and / or past conversations about the subject of CPR. Measured over time and across interactions, the overall quality of shared decision-making may have been far greater. The study design would be further strengthened by adding a (randomized) control group to determine the effectiveness of the CPR-VDA intervention. In this study, the CPR-VDA was not compared to usual practice or to a control group, and did not randomize the selection of the subjects.

Preparing each member of the healthcare team to support the decision-making process may further support shared decision-making. The lack of team member participation was particularly evident by the lack of support provided to physicians by other healthcare team members. Physician members of the healthcare team working at the dialysis center had no instruction or practice using the CPR-VDA and only received a brief overview of the research project from the study nurse. Training in the use of shared decision-making and decision aids may have improved uptake and use of CPR-VDA in the clinical setting. Future interventions and pragmatic effectiveness evaluation could focus on ensuring that healthcare team members are supported to implement the CPR-VDA.

Finally, although this study was formulated around how to best support decision-making about the CPR decision, the decision-making process around life-saving interventions or end-of-life care is not just about arriving at the decision. The decision-making process involves patients and families receiving support for their grief while receiving information about loss, potential loss, or change of health status. The use of the decision aid seemed to open space for other conversations about end-of-life and grieving, which were supported by the study nurse. Anticipatory bereavement was first described by Lindemann [29] as observations of preparatory grief work done by wives with husbands at war and further conceptualized as a process to prepare terminally ill patients and their families for death thus aiding grieving [30]. However, most of the research around anticipatory bereavement involves caregivers with very little research focusing on the patients experience with end-of-life decision-making and anticipatory bereave 
ment [31]. A future study may be able to reveal connections between the use of patient and family decision support around end-of life care and anticipatory bereavement.

\section{Conclusions}

The CPR-VDA was feasible and acceptable to patients with ESRD, their families and the healthcare team. The CPR-VDA positively affected decision-making: improving patient and family knowledge about CPR, clarity of values, patients' decisional self-efficacy, the congruence between documented physician's orders and patient choice, quality of communication about CPR, while reducing decisional conflict (uncertainty) amongst patients, families, and physicians. The CPR-VDA was useful to patients regardless of their ability to engage in meaningful conversations with their family and the healthcare team about whether or not to have CPR as part of their care.

\section{Abbreviations}

CPR: Cardiopulmonary resuscitation; CPR-VDA: Cardiopulmonary resuscitation video decision aid; ESRD: End stage renal disease; IP-SDM: Interprofessional shared decision-making model; VDA: Video decision aid

\section{Acknowledgements}

We would like to thank the patients, family members and healthcare professionals who participated in this study.

\section{Funding}

The research project was supported by The Heart and Stroke Foundation of Canada as part of a larger project, and CKB was supported by an Allied Health Grant from The Kidney Foundation of Canada. Funding agencies had no role in the design, enrollment, data collection, analysis, or writing of manuscript or decision to publish the research. The content is solely the responsibility of the authors.

\section{Availability of data and materials}

The datasets generated and/or analysed during the current study are not publicly available due to concerns protecting personal information of participating physicians/patients/families.

\section{Authors' contributions}

JK and CKB designed the study, and CKB implemented the study with the guidance and support of JK. JK and CKB met with stakeholders to gain support for the study in each practice setting. CKB recruited, enrolled, and collected data from all participants. CKB inputted and analyzed the data with support from JK and WM. JK, CKB, and WM assisted with feedback and edits to the manuscript, and preparing it for publication. All authors read and approved the final manuscript.

\section{Ethics approval and consent to participate}

University of Saskatchewwan Research Ethics Board approval (BEH-13-200) was obtained prior to commencing the study and all participants provided written informed consent. Saskatoon Health Region Nephrology (Hemodialysis) patient and family advisory council and Nephrology division partners also approved the study.

\section{Consent for publication}

Not Applicable - all data is in aggreate form

\section{Competing interests}

The authors declare that they have no competing interests.

\section{Publisher's Note}

Springer Nature remains neutral with regard to jurisdictional claims in published maps and institutional affiliations.

\section{Author details}

${ }^{1}$ Manager 5A Surgery and Ambulatory Care, St. Paul's Hospital, 1702 20th Street West, Saskatoon, SK S7M OZ9, Canada. ${ }^{2}$ School of Nursing and Centre for Health Services and Policy Research, The University of British Columbia, T275- 2211 Wesbrook Mall, Vancouver, BC V6T 2B5, Canada. ${ }^{3}$ College of Nursing, University of Saskatchewan, PO Box 6, 104 Clinic Place, Saskatoon, SK S7N 2Z4, Canada.

Received: 5 September 2017 Accepted: 28 August 2018

Published online: 12 September 2018

\section{References}

1. Murray MA, Bissonnette J, Kryworuchko J, Gifford W, Calverley S. Whose choice is it? Shared decision making in nephrology care. Semin Dial. 26: Wiley Online Library, 2013:169-74.

2. The Kidney Foundation of Canada [https://www.kidney.ca/].

3. Herzog CA. Cardiac arrest in dialysis patients: approaches to alter an abysmal outcome. Kidney Int. 2003;63:S197-200.

4. Davison SN. Advance care planning in patients with end-stage renal disease. Prog Palliat Care. 2009;17(4):170-8.

5. Lafrance J-P, Nolin L, Senécal L, Leblanc M. Predictors and outcome of cardiopulmonary resuscitation (CPR) calls in a large haemodialysis unit over a seven-year period. Nephrol Dial Transplant. 2005;21(4):1006-12.

6. Ehlenbach WJ, Barnato AE, Curtis JR, Kreuter W, Koepsell TD, Deyo RA, Stapleton RD. Epidemiologic study of in-hospital cardiopulmonary resuscitation in the elderly. N Engl J Med. 2009;361(1):22-31.

7. Larkin GL, Copes WS, Nathanson BH, Kaye W. Pre-resuscitation factors associated with mortality in 49,130 cases of in-hospital cardiac arrest: a report from the National Registry for cardiopulmonary resuscitation. Resuscitation. 2010;81(3):302-11.

8. Sehatzadeh S. Cardiopulmonary resuscitation in patients with terminal illness: an evidence-based analysis. Ontario Health Technol Assess Ser. 2014; 14(15):1.

9. Jones DS, Podolsky SH, Greene JA. The burden of disease and the changing task of medicine. N Engl J Med. 2012;366(25):2333-8.

10. Heyland DK, Frank C, Groll D, Pichora D, Dodek P, Rocker G, Gafni A. Understanding cardiopulmonary resuscitation decision making: perspectives of seriously ill hospitalized patients and family members. Chest J. 2006; 130(2):419-28.

11. Luckett T, Sellars M, Tieman J, Pollock CA, Silvester W, Butow PN, Detering KM, Brennan F, Clayton JM. Advance care planning for adults with CKD: a systematic integrative review. Am J Kidney Dis. 2014;63(5):761-70.

12. Tong A, Cheung KL, Nair SS, Tamura MK, Craig JC, Winkelmayer WC. Thematic synthesis of qualitative studies on patient and caregiver perspectives on end-of-life care in CKD. Am J Kidney Dis. 2014;63(6):913-27.

13. Muthalagappan S, Johansson L, Kong WM, Brown EA. Dialysis or conservative care for frail older patients: ethics of shared decision-making. Nephrol Dial Transplant. 2013;28(11):2717-22.

14. Wennberg JE, Fisher ES, Goodman DC, Skinner JS. Tracking the care of patients with severe chronic illness-the Dartmouth atlas of healthcare 2008. Lebanon, NH: The Dartmouth Institute for Health Policy \& Clinical Practice; 2008.

15. Volk RJ, Llewellyn-Thomas H, Stacey D, Elwyn G. Ten years of the international patient decision aid standards collaboration: evolution of the core dimensions for assessing the quality of patient decision aids. BMC Med Inform Decis Mak. 2013;13(2):S1.

16. Stacey $D$, Légaré $F$, Lewis $K$, Barry MJ, Bennett $C L$, Eden $K B$, Holmes-Rovner M, Llewellyn-Thomas H, Lyddiatt A, Thomson R, Trevena L. Decision aids for people facing health treatment or screening decisions. Cochrane Database Syst Rev. 2017(4). https://doi.org/10.1002/14651858.CD001431.pub5.

17. Frank C, Pichora D, Suurdt J, Heyland D. Development and use of a decision aid for communication with hospitalized patients about cardiopulmonary resuscitation preference. Patient Educ Couns. 2010;79(1):130-3.

18. Stacey D, Kryworuchko J, Belkora J, Davison BJ, Durand M-A, Eden KB, Hoffman AS, Koerner M, Légaré F, Loiselle M-C. Coaching and guidance with patient decision aids: a review of theoretical and empirical evidence. BMC Med Inform Decis Mak. 2013;13(2):S11. 
19. Barry MJ, Fowler FJ Jr, Mulley AG Jr, Henderson JV Jr, Wennberg JE. Patient reactions to a program designed to facilitate patient participation in treatment decisions for benign prostatic hyperplasia. Med Care. 1995;33(8):771-82.

20. Sepucha KR, Ozanne EM, Partridge AH, Moy B. Is there a role for decision aids in advanced breast cancer? Med Decis Mak. 2009;29(4):475-82.

21. Cranney A, O'Connor AM, Jacobsen MJ, Tugwell P, Adachi JD, Ooi DS, Waldegger L, Goldstein R, Wells GA. Development and pilot testing of a decision aid for postmenopausal women with osteoporosis. Patient Educ Couns. 2002;47(3):245-55.

22. O'Connor AM. Validation of a decisional conflict scale. Med Decis Mak. 1995; 15(1):25-30

23. Légaré F, Kearing S, Clay K, Gagnon S, D'Amours D, Rousseau M, O'Connor A. Are you SURE? Can Fam Physician. 2010;56(8):e308-14.

24. Elwyn G, Hutchings H, Edwards A, Rapport F, Wensing M, Cheung WY, Grol R. The OPTION scale: measuring the extent that clinicians involve patients in decision-making tasks. Health Expect. 2005;8(1):34-42.

25. El-Jawahri A, Podgurski LM, Eichler AF, Plotkin SR, Temel JS, Mitchell SL, Chang Y, Barry MJ, Volandes AE. Use of video to facilitate end-of-life discussions with patients with cancer: a randomized controlled trial. J Clin Oncol. 2009;28(2):305-10.

26. Volandes AE, Brandeis GH, Davis AD, Paasche-Orlow MK, Gillick MR, Chang Y, Walker-Corkery ES, Mann E, Mitchell SL. A randomized controlled trial of a goals-of-care video for elderly patients admitted to skilled nursing facilities. J Palliat Med. 2012;15(7):805-11.

27. Volandes AE, Paasche-Orlow MK, Barry MJ, Gillick MR, Minaker KL, Chang Y, Cook EF, Abbo ED, El-Jawahri A, Mitchell SL. Video decision support tool for advance care planning in dementia: randomised controlled trial. Bmj. 2009; 338:b2159.

28. Canadian Nurses Association. Code of Ethics for Registered Nurses. Ottawa, ON: Author; 2008

29. Lindemann E. Symptomatology and management of acute grief. Am J Psychiatr. 1944;101(2):141-8.

30. Kübler-Ross E. On death and dying. London: Tavistock/Routledge; 1989.

31. Nielsen MK, Neergaard MA, Jensen AB, Bro F, Guldin M-B. Do we need to change our understanding of anticipatory grief in caregivers? A systematic review of caregiver studies during end-of-life caregiving and bereavement. Clin Psychol Rev. 2016;44:75-93.

Ready to submit your research? Choose BMC and benefit from:

- fast, convenient online submission

- thorough peer review by experienced researchers in your field

- rapid publication on acceptance

- support for research data, including large and complex data types

- gold Open Access which fosters wider collaboration and increased citations

- maximum visibility for your research: over $100 \mathrm{M}$ website views per year

At $\mathrm{BMC}$, research is always in progress.

Learn more biomedcentral.com/submissions 